\title{
Introduction: Reasoning, Argumentation, and Critical Thinking Instruction
}

\author{
Frank Zenker ${ }^{1,2,3}$
}

Published online: 14 July 2016

(C) Springer Science+Business Media Dordrecht 2016

\section{Rationale}

In a widely noted article, Daniel Willingham (2007) has aptly stated that "[v]irtually everyone would agree that a primary, yet insufficiently met, goal of schooling is to enable students to think critically" (p. 8). Indeed, particularly the heuristics and biases-program in experimental psychology, but also anecdotal evidence from industry, support the view that humans by and large manage, and can even strive, despite systematically falling prey to various forms of cognitive and social biases. But while broad agreement is more easily reached that our natural reasoning abilities should be improved-notably through critical thinking (CT) instruction at college- and university-levela consensus on how improvements may be reliably brought about is far less readily had. Nor will this surprise, for those seeking to design requisite CT-curricula must currently find the sound part of the evidential basis in support of teaching methods that reliably ameliorate the status quo to be embarrassingly thin. Compared to research supporting the presence of biases in reasoning and decision making, work reporting on how such biases can be overcome has remained dishearteningly rare.

To make matters worse, said research has of late been "imported" into CT-instruction in ways that do not always

Frank Zenker

frank.zenker@fil.lu.se

1 Department of Philosophy and Cognitive Science, Lund University, LUX, Box 192, 22100 Lund, Sweden

2 Philosophie, Universität Konstanz, Postfach D9, 78457 Constance, Germany

3 Institute of Philosophy, Slovak Academy of Sciences, Klemensova 19, 81364 Bratislava, Slovak Republic deserve the predicate 'critical'. Exceptions granted, current undergraduate and graduate populations are regularly being subjected to a popularized version of the heuristics and biases program, which often merely extends the already problematic tradition of drawing up lists of fallacies. Likewise, recent advances in modelling natural language argumentation by formal means have largely remained outside the standard curriculum, and so cannot readily be drawn upon in evaluating argumentation. Similar things hold for argument reconstruction and visualization software, which are not part of the standard curriculum either. Nor does it help that, in response to CT-instruction having become mandatory especially on U.S. campuses-whether as dedicated courses or across the curriculum-the term 'critical thinking' often means various things to various people.

Though critical thinking had (perhaps rather naively) been conceived primarily as an educational goal, CT-instruction may be expected to increasingly respond to diverging socio-political interests, with CT-books, CT-aptitude tests, and CT-consultancy services competing narrowly for their share of a sizable education-industry as well as, more broadly, for true intellectual impact.

\section{Chapter Overview}

Urging that CT-curriculum designers take debiasing (more) seriously, in "The Scope of Debiasing in the Classroom" Guillaume Beaulac and Tim Kenyon expand the range of teachable critical thinking strategies, and introduce socially-implemented and socially maintained reasoning infrastructure, while retaining successful individualistic approaches. Besides a four-levelled taxonomy of debiasing strategies, they offer a selection of potentially effective teaching approaches and techniques. 
Presenting an approach to debiasing that is meant to complement Beaulac and Kenyon's, in "Contextual Debiasing and Critical Thinking: Reasons for Optimism" Vasco Correia argues that, though we may currently lack wellhardened knowledge as to which debiasing techniques are most appropriate in view of given biases and contexts, those engaged in CT-instruction have reason to be confident that such instruction does in fact ameliorate biases on the whole.

In "The Pros and Cons of Identifying Critical Thinking with System 2 Processing," Jean-François Bonnefon addresses the currently particularly popular two systemsdistinction in view of CT, and points out that system 2 reasoning-being generally considered deliberate, slower, and more effortful than system 1 reasoning-plausibly provides a necessary condition for CT. But extant research results make it implausible to suppose that system 2 reasoning provides a sufficient condition for CT.

Focusing on an important knowledge gap — arising since it is one thing to observe students scoring low on standardized CT-tests, but quite another to infer the exact skill set they lack - in "A Role for Reasoning in a Dialogic Approach to Critical Thinking" Deanna Kuhn counters the current trend of viewing reasoning as a broadly social affair, and presents empirical evidence documenting a role for individual reasoning competencies in supporting the effectiveness of reasoned discourse.

Further refining Deanna Kuhn's foundational research, in "Assessing Levels of Epistemological Understanding: the Standardized Epistemological Understanding Assessment (SEUA)" Natalia Żyluk, Karolina Karpe, Mikotaj Michta, Weronika Potok, Katarzyna Paluszkiewicz, and Mariusz Urbański present an adaptation of Kuhn's original assessment-instrument. Through enhancing the original's reliability and increasing its ecological validity, it recommends itself as an improved alternative for purposes of assessing an individual's level of epistemological understanding.

Deploying a model of strategic reasoning-called 'heuristic rhetoric' - in “Cicero on Pompey's Command: Heuristic Rhetoric and Teaching the Art of Strategic Reasoning" Gabor Tahin demonstrates the model's merits in view of a paradigmatic textual example from the rhetorical tradition that can serves in contemporary classrooms not only to teach argumentation skills, but also to improve students' recognition of fallacies and to increase their awareness of an audience's biases.

In "Promoting Critical Thinking in Higher Education" Clarence Burton Sheffield Jr. reflects on his experiences as the inaugural Eugene H. Fram Chair in Applied Critical Thinking at Rochester Institute of Technology, N.Y, USA - which, to date, is the only academic chair-position dedicated to this purpose. Besides reporting on his campuswide initiatives in this role, and their effects, the insights he relates should be of particular service to those who face similar challenges in comparable roles.

In "Critical Thinking Across the Curriculum: A Vision" Robert Ennis lays out a vision for, and details the required infrastructure in order to implement, a higher education program for critical thinking across the curriculum. This proposal markedly differs from a dedicated CT course, which is the standard today, at least in that the combination of CT-instruction with subject-matter instruction promises better results for $\mathrm{CT}$, and possibly also for subject-matter learning and retention.

In "Stimulating Reflection and Self-Correcting Reasoning through Argument Mapping," Michael H.G. Hoffmann focuses on improving one's own reasoning as one important CT-component that has not seen much attention in the past. Based on research showing that students hardly ever engage in substantial revisions of their work, Hoffmann reviews extant explanations and discusses the design of computer-supported argument visualization (CSAV) that stimulate reflection and self-correction.

Yara Yasser Hilal addresses concerns regarding the extent to which the aims and objectives of academic programs align with pedagogies for CT in "Do Programmes Delineating Critical Thinking as a Learning Outcome Facilitate its Teaching?" Based on semi-structured interviews, questionnaires, and class visits, her case study compares the international baccalaureate diploma program with the Lebanese baccalaureate program, and identifies a number of unsolved challenges these programs face.

Acknowledgments Some among the contributors to this special issue met 25-27 February, 2015 at Lund University, Sweden, for an interdisciplinary conference held under the same title as this chapter (see https://ract2015.wordpress.com), with additional contributions having arisen in response to an open call for papers. I thank audiences at this event for a fruitful discussion, as well as the Swedish Research Council (VR), the Grace and Philipp Sandblom Fund, the Elisabeth Rausing Memorial Fund, and the Association for Informal Logic and Critical Thinking (AILACT) for financial support. Moreover, I remain indebted to a sizable number of anonymous reviewers for having provided invaluable assistance when selecting papers for this meeting and during the publication process. Finally, thanks to Topoi's editor in chief, Fabio Paglieri, for agreeing to publish a broad range of papers across various disciplines.

\section{Reference}

Willingham D (2007) Critical thinking: why is it so hard to teach? Am Educ 31(2):8-19. (reprinted as: Willingham, D.T. (2008). Critical thinking: Why is it so hard to teach? Arts Education Policy Review, 109 (4): 21-32.) 